\title{
POLINSAR BASED SCATTERING INFORMATION RETRIEVAL FOR FOREST ABOVEGROUND BIOMASS ESTIMATION
}

\author{
${ }^{1}$ N. Agrawal ${ }^{*},{ }^{2}$ S. Kumar, ${ }^{3}$ V. A. Tolpekin \\ ${ }^{1,2}$ Indian Institute of Remote Sensing, Department of Space, Dehradun, India - agrawal33605@alumni.itc.nl, shashi@iirs.gov.in ${ }^{3}$ \\ Faculty of Geo-Information Science and Earth Observation (ITC), University of Twente, The Netherlands - \\ v.a.tolpekin@utwente.nl
}

KEY WORDS: Extended Water Cloud Model (EWCM), PolInSAR, Biomass, Backscatter, Water Cloud Model (WCM), Polarization orientation angle shift.

\begin{abstract}
:
Forests play a crucial role in storing carbon and are of paramount importance in maintaining global carbon cycle. Assessment of forest biomass at regional and global level is vital for understanding and monitoring health of both tree species and entire cover. Changes in forest biomass are caused by human activities, natural factors and variations in climate. Forest biomass measurement is necessary for gauging the changes in forest ecosystems. Remote sensing is indispensable for mapping forest biophysical parameters. Microwaves are capable of collecting data even in case of cloud cover as the microwaves are of long wavelength. Microwaves help in retrieving scattering information of target. The goal of this research was to map aboveground biomass (AGB) over Barkot forest range in Dehradun, India. The current work focuses on the retrieval of PolInSAR based scattering information for the estimation of aboveground biomass. Radarsat-2 fully Polarimetric C-band data was used for the estimation of AGB in Barkot forest area. A semi-empirical model, which is Extended Water Cloud Model (EWCM) was utilized for AGB estimation. EWCM considers ground-stem interactions. Due to overestimation of volume scattering, polarization orientation angle shift correction was implemented on the PolInSAR pair. Field biomass data was utilized for accuracy assessment. The results show that coefficient of determination $\left(\mathrm{R}^{2}\right)$ value of 0.47 , Root Mean Square Error (RMSE) of $56.18\left(\mathrm{t} \mathrm{ha}^{-1}\right)$ and accuracy of $72 \%$ was obtained between modelled biomass against field measured biomass. Hence, it can be inferred from the obtained results that PolInSAR technique, in combination with semi-empirical modelling approach, can be implemented for estimating forest biomass.
\end{abstract}

\section{INTRODUCTION}

Forests are the most vital renewable resources which play a substantial role in the existence of humans and the ecosystem (FAO, 2012). They cover about 33\% of the total surface and play a major role in balancing global carbon cycle by exchanging of carbon (FAO, 2012). Forests help in preserving the delicate balance of the local ecosystem. They also reduce the damage caused by natural disasters such as floods and avalanches. Forests however, are under stress due to the changing temperature and precipitation patterns, among other reasons. Therefore, continuous monitoring of the exact amount of these resources have to be maintained (Kirilenko and Sedjo, 2007). Biomass is an important parameter in evaluating the health of forests (MainKnorn et al., 2011). Biomass of forest includes the sum of biomass which is above the ground and below the ground (FAO, 2012). Biomass estimation of forest through conventional (insitu) method is a difficult and time-consuming task. Researchers have developed remote sensing-based modelling approaches for AGB estimation. Mainly three regions of the Electromagnetic (EM) spectrum are used in remote sensing for forest mapping and monitoring and these regions are; visible, thermal and microwave.

Synthetic aperture radar (SAR) sensor transmits electromagnetic radiation in microwave range of EM spectrum and receives the backscattered radiation after interaction with the objects on earth's surface. SAR sensor has an added advantage of forest canopy penetration and due to this penetration capability, it is widely used for forest biophysical parameter retrieval.

Polarimetric Synthetic aperture radar (PolSAR) has successfully proved its potential in modelling approaches for forest biophysical parameters retrieval, stem volume and biomass (Amrutkar et al., 2012) (Wollersheim and Collins, 2008). For the estimation of AGB of the forest area, researchers are currently using a combination of PolSAR decomposition and Polarimetric SAR interferometry (PolInSAR). These techniques are able to discriminate the backscattering from the objects lying in the same pixel leading to reliable scattering information for parameters retrieval.

In remote monitoring using airborne or satellite data, the vegetation parameters extraction like forest height (Hellmann and Cloude, 2005) and biomass (Mette et al., 2004), PolInSAR has vital applications. PolInSAR combines two radar technologies such as SAR polarimetry and SAR interferometry. Polarimetry involves measuring the backscatter received from all four Polarimetric combinations $(\mathrm{HH}, \mathrm{VV}, \mathrm{VH}$ and $\mathrm{HV}$ ) (Cloude and Pottier, 1996). Using this, a $2 \times 2$ scattering matrix is retrieved which is then used to calculate image pixel (backscatter) value for any polarization combination (Cloude, 2008).

Decomposition modelling technique is used for retrieving the scattering elements. There are two types of decomposition modelling, namely, coherent decomposition and incoherent

\footnotetext{
* Corresponding author
} 
decomposition (Touzi et al., 2004) (Touzi, 2007). Coherent decomposition is able to characterize only the coherent targets which gives completely polarized backscatter, also known as point or pure scatterer (Touzi et al., 2004). Incoherent decomposition occurs in natural objects like in forest/vegetation areas which is characterized by coherency matrix. Three types of scattering mechanisms, namely, surface scattering, double bounce and volume scattering are explained by the FreemanDurden decomposition model (Freeman and Durden, 1998). On the other hand, the Yamaguchi decomposition model (Yamaguchi et al., 2011) considers four scattering mechanisms, namely, surface, double-bounce, volume and helix scattering. Multiple component scattering models (Zhang et al., 2008) consider five scattering mechanisms, namely, surface, doublebounce, volume, helix and wire scattering.

PolSAR and PolInSAR based semi-empirical models have been used for forest $\mathrm{ABG}$, stem volume and tree height estimation (Chowdhury et al., 2013) (Dinh et al., 2012). For AGB estimation, a Water Cloud Model (WCM) was developed by Attema and Ulaby., (Attema and Ulaby, 1978), which was further improved upon and used by many researchers. PolInSAR coherence based random volume over ground (RVoG) and interferometric water cloud model (IWCM) models were used for forest parameter retrieval using scattering elements modelling (Papathanassiou and Cloude, 2001) (Cloude and Papathanassiou, 1998) (Santoro, 2003). In this study the concept of PolInSAR based scattering in semi-empirical modelling is utilized for AGB estimation.

Fully Polarimetric SAR data is used for scattering information retrieval from single SAR resolution cell. Single SAR resolution cell may contain contributions from more than one scattering objects. Hence, single or dual polarised data does not provide all the possible scattering information. To overcome this problem fully polarimetric data is used. Fully polarimetric data of different dates provide different scattering values for same object. Scattering values are important input elements for modelling of forest aboveground biomass. In this study, an approach is proposed to get reliable scattering from PolSAR data using interferometric pair. Innovation is aimed at modelling of AGB in a tropical forest using PolInSAR based scattering information.

Polarimetry is a measurement and explanation of polarization state of electromagnetic waves. In SAR remote sensing Polarimetric combinations are defined on the basis of the polarization state of transmitted and received signals. Cloude and Papathanassiou (Cloude and Papathanassiou, 1998) utilized the polarimetry for generation of coherent interferometry. The optimization of coherence is performed in order to determine the best scattering elements. The interferogram were generated which were independent of scattering elements. Chen et al., (Chen et al., 2012) presented a methodology to find out complex coherence. This complex coherence matrix follows Wishart distribution. Two types of information i.e. polarimetric information and interferometric information are used as a measure to search for homogeneous pixels in PolInSAR image.

Scattering matrix describes polarization value derived using polarization combinations. Backscattered values retrieved from polarized SAR data for any location is influenced by wavelength of SAR system, orientation, surface roughness and moisture condition of objects lying in the particular location. Scattering matrix is given in equation 1 .

$$
S=\left[\begin{array}{ll}
S_{H H} & S_{H V} \\
S_{V H} & S_{V V}
\end{array}\right]
$$

The four elements scattering matrices are obtained for every pixel. These elements can be retrieved from particular polarimetric combinations of SAR data. SAR systems work on two types of configurations: monostatic \& bistatic. Monostatic systems have single antenna by which they transmit and receive signals while bistatic systems have separate antennas for transmitting and receiving signals (Lee and Pottier, 2009). According to assumption of reciprocity $S_{H V}=S_{V H}$ and only three polarimetric channels are independent in $\mathrm{S}$ (Woodhouse, 2006).

' $\mathrm{S}$ ' is only effective for coherent targets, whereas coherency and covariance matrices are effective for analysing complex targets (Touzi et al., 2004). Polarimetric parameters of complex targets can be retrieved using a coherency matrix. It vectorised form of the scattering matrix $\mathrm{S}$ and its multiplication with the complex conjugate transpose is shown 4 (Woodhouse, 2006). All nine components of $\mathrm{C}$ contain physical information of the target. Coherency matrix and covariance matrix are represented as Pauli and Lexicographic basic. Lexicographic configures both the cross-polarized channels with the similar information. In the Lexicographic condition, covariance matrix $\mathrm{C}$ is given in equation 4.

$$
\begin{aligned}
& K_{L}=\left[\begin{array}{c}
S_{H H} \\
\sqrt{2} S_{H V} \\
S_{V V}
\end{array}\right] \\
& C=K_{L} \cdot K_{L}^{T} \\
& C=\left[\begin{array}{ccc}
<\left|S_{H H} \cdot S_{H H}{ }^{*}\right|> & \sqrt{2}<S_{H H} \cdot S_{H V}{ }^{*}> & <S_{H H} \cdot S_{V V}{ }^{*}> \\
\sqrt{2}<S_{H V} \cdot S_{H H}{ }^{*}> & 2<\left|S_{H V} \cdot S_{H V}{ }^{*}\right|> & \sqrt{2}<S_{H V} \cdot S_{V V}{ }^{*}> \\
<S_{V V} \cdot S_{H H}{ }^{*}> & \sqrt{2}<S_{V V} \cdot S_{H V}{ }^{*}> & <\left|S_{V V} \cdot S_{V V}{ }^{*}\right|>
\end{array}\right] \\
& K_{P}=\frac{1}{\sqrt{2}}\left[\begin{array}{c}
S_{H H}+S_{V V} \\
S_{H H}-S_{V V} \\
2 S_{H V}
\end{array}\right]
\end{aligned}
$$

In the Pauli condition, coherency matrix $\mathrm{T}$ is given in equation 6.

$$
=\left[\begin{array}{ccc}
\left.<\left|S_{H H}+S_{V V}\right|^{2}\right\rangle & <\left(S_{H H}+S_{V V}\right)\left(S_{H H}-S_{V V}\right)^{T}> & 2<\left(S_{H H}+S_{V V}\right) S_{H V}{ }^{T}> \\
\left\langle\left(S_{H H}-S_{V V}\right)\left(S_{H H}+S_{V V}\right)^{T}\right\rangle & <\left|S_{H H}-S_{V V}\right|^{2}> & \left.2<\left(S_{H H}-S_{V V}\right) S_{H V}{ }^{T}\right\rangle \\
\left.2<S_{H V}\left(S_{H H}-S_{V V}\right)^{T}\right\rangle & 2<S_{H V}\left(S_{H H}+S_{V V}\right)^{T}> & \left.4<\left|S_{H V}\right|^{2}\right\rangle
\end{array}\right]
$$

Multilooking of the data is applied directly on covariance/coherency matrix and in this way includes ensemble averaging $(<>)$.

\section{PolInSAR (Polarimetric SAR Interferometry)}

PolSAR and PolInSAR based semi-empirical models have been used for forest $\mathrm{ABG}$, stem volume and tree height estimation (Chandola, 2014).

\section{Semi-empirical scattering model}

Semi-empirical scattering model can be expressed in terms of scattering matrix element for surface and volume scattering. The WCM relates forest parameters and forest backscatter. The assumptions considered by this model are that vegetation behaves like a homogeneous medium similar to a water droplet filled in a water cloud over a horizontal plane (Attema and Ulaby, 1978). 
This ground is modelled as plane and the forest scattering elements relate to water droplets in water cloud. Initially, some part of the incoming incident energy is reflected back to the sensor and the rest transmitted to the lower vegetation layer along with attenuation in terms of total forest backscatter.

$$
\sigma_{\text {total }}^{0}=e^{-\tau B} \sigma_{g r}^{0}+\left(1-e^{-\tau B}\right) \sigma_{v e g}^{0}
$$

Where, $\sigma_{\text {total }}^{0}$ is the total SAR backscatter, $\tau$ is empirically derived and is function of two-way transmissivity, $B$ is aboveground biomass, $\sigma_{\mathrm{gr}}^{0}$ is scattering from ground, $\sigma_{\mathrm{veg}}^{0}$ is scattering from vegetation and it includes double-bounce and volume scattering.

\section{Extended water cloud model}

Double bounce scattering because of the scattering from ground to stem of the tree should be considered for accurate biomass estimation which is not modelled in WCM (Poolla, 2013).

This the final equation of EWCM to find empirically defined coefficient $(\beta)$ and AGB (B) (Poolla, 2013).

$$
\sigma_{\text {for }}^{0}=\sigma_{g r}^{0} e^{-\beta B}+\sigma_{v e g}^{0}\left(1-e^{-\beta B}\right)+\sigma_{g s}^{0} e^{-\beta B}
$$

\section{METHODOLOGY AND APPROACH}



Figure 1: Flow Diagram of Methodology

The PolInSAR data processing was carried out in several stages. First of all, scattering matrix was generated for both master and slave image. Co-registration was then performed for SAR image pair. Next, PolInSAR based coherency matrix was generated for the co-registered images. PolInSAR image was De-orientated and decomposition of de-oriented image was then done. Finally, from decomposition three scattering elements i.e. surface scattering, volume scattering and double-bounce scattering were extracted. These parameters were given as input to EWCM model for estimating biomass. The field data and modelled biomass were compared to each other. Accuracy assessment was done using RMSE and percent accuracy.

PolInSAR image was generated by using SAR images (Master image and slave image) using interferometry. Master image is taken from January 28, 2014 and slave image is taken from February 20, 2014. Scattering matrix generated from Master and Slave images is given in equation 1 and 2 respectively. Both the images are taken from the same range for the diverse plots in two distinctive time periods. Table 4 illustrates all the information related to master and slave images.

$$
\begin{aligned}
& {\left[\mathrm{S}_{\mathrm{M}}\right]=\left[\begin{array}{ll}
\mathrm{S}_{\mathrm{HH}}^{\mathrm{M}} & \mathrm{S}_{\mathrm{HV}}^{\mathrm{M}} \\
\mathrm{S}_{\mathrm{VH}}^{\mathrm{M}} & \mathrm{S}_{\mathrm{VV}}^{\mathrm{M}}
\end{array}\right]} \\
& {\left[\mathrm{S}_{\mathrm{S}}\right]=\left[\begin{array}{ll}
\mathrm{S}_{\mathrm{HH}}^{\mathrm{S}} & \mathrm{S}_{\mathrm{HV}}^{\mathrm{S}} \\
\mathrm{S}_{\mathrm{VH}}^{\mathrm{S}} & S_{\mathrm{VV}}^{\mathrm{S}}
\end{array}\right]}
\end{aligned}
$$

Where, $\mathrm{M}$ is a master image, $\mathrm{S}$ is a slave image and $\mathrm{B}$ is a baseline showing distance in the middle of two platforms.

\section{Co registration of master and slave image}

Image co-registration is significant part of PolInSAR data processing, used for the alignment of two SAR images to get their phase difference. Co-registration is applied on SAR image pair (Li and Bethel, 2008).

\section{PolInSAR based coherency matrix}

Berman and Sanchez (Ballester-Berman and Lopez-Sanchez, 2010) presented a method to generate covariance matrix using PolInSAR pair of Radarsat-2 dataset. The covariance matrix generated with the help of lexicographic matrixes obtained from PolInSAR pair and Freeman-Durden three-component model was adopted to generate surface, double-bounce and volume scattering elements.

Previously all the decomposition models were developed using covariance matrix. After getting the sensitivity of POA (Lee and Ainsworth, 2011) of SAR data with coherency matrix element all the decomposition modelling are again redefined in terms of coherency matrix elements. An approach to get coherency matrix elements from PolInSAR pair was implemented to get scattering elements from coherency matrix-based Yamaguchi four component decomposition model (Yamaguchi et al., 2011). The advantage of coherency matrix is revealed in a work of Yamaguchi.

PolInSAR based coherency matrix $(\mathrm{T})$ was generated with the help of co-registered Master and Slave images. Pauli feature vector of master image $K_{M}$ was multiplied with the transpose of complex conjugate of slave image $K_{S}^{t^{*}}$ (Ballester-Berman and Lopez-Sanchez, 2010). The decomposition of T was done using the four components Yamaguchi decomposition. All the components of the decomposition are Hermitian, and the $\mathrm{T}$ is not Hermitian matrix as given in equation 14. Some assumptions were considered in the coherency matrix to justify this statement. The modulus of diagonal elements of the coherency matrix were taken to avoid the ambiguity of Hermitian matrix property. According to the properties of Hermitian matrix ("Hermitian 
matrix," 2015) diagonal elements must be real and PolInSAR based coherency matrix diagonal elements are not real. To preserve the properties of PolInSAR based coherency matrix following assumption was made where modulus of diagonal elements of $\mathrm{T}$ were taken.

Off diagonal elements of lower triangular part of coherency matrix were assumed to be similar to the complex conjugate of the corresponding element in off diagonal element of upper triangular part of coherency matrix.

Coherency matrix based four component decompositions developed by Yamaguchi et al. (Yamaguchi et al., 2011) includes 6 elements $\left(T_{11}, T_{12}, T_{13}, T_{22}, T_{23}\right.$ and $\left.T_{33}\right)$ of coherency matrix. The same six elements were considered for four component decompositions using PolInSAR based coherency matrix. For future recommendation all the nine elements of coherency matrix can be used.

PolInSAR coherency matrix is not Hermitian. Thus, to continue the process of decomposition, off-diagonal elements $\left(T_{21}, T_{31}\right.$, $\mathrm{T}_{32}$ ) were discarded. In this modelling one assumption was made that the elements $\left(\mathrm{T}_{12}=\mathrm{T}_{21} *\right),\left(\mathrm{T}_{13}=\mathrm{T}_{31} *\right)$ and $\left(\mathrm{T}_{23}=\mathrm{T}_{32} *\right)$. PolInSAR coherency matrix was generated by in a separate procedure and the elements of generated matrix were used as an input in the software PolSAR Pro for Yamaguchi four component decomposition. The decomposition method was adapted from Yamaguchi et al (Yamaguchi et al., 2011).

$$
\begin{aligned}
& \mathrm{T}=\mathrm{K}_{\mathrm{M}} \cdot \mathrm{K}_{\mathrm{S}}^{\mathrm{t}^{*}} \\
& K_{M}=\frac{1}{\sqrt{2}}\left[\begin{array}{c}
S_{H H}{ }^{M}+S_{V V}{ }^{M} \\
S_{H H}{ }^{M}-S_{V V}{ }^{M} \\
2 S_{H V}{ }^{M}
\end{array}\right] \\
& \mathrm{K}_{\mathrm{S}}^{\mathrm{t}^{*}}=\frac{1}{\sqrt{2}}\left[\mathrm{~S}_{\mathrm{HH}} \mathrm{S}+\mathrm{S}_{\mathrm{VV}}{ }^{\mathrm{S}} \mathrm{S}_{\mathrm{HH}} \mathrm{S}-\mathrm{S}_{\mathrm{VV}} \mathrm{S} 2 \mathrm{~S}_{\mathrm{HV}}{ }^{\mathrm{S}}\right]^{*}
\end{aligned}
$$

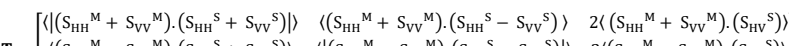

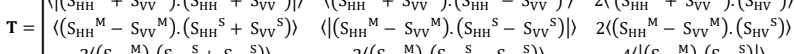

$$
\begin{aligned}
& 2\left\langle\left(\mathrm{~S}_{\mathrm{HV}}{ }^{\mathrm{M}}\right) \cdot\left(\mathrm{S}_{\mathrm{HH}}{ }^{\mathrm{S}}+\mathrm{S}_{\mathrm{VV}}{ }\right)\right. \\
& 2\left\langle\left(\mathrm{~S}_{\mathrm{HV}}{ }^{\mathrm{M}}\right) \cdot\left(\mathrm{S}_{\mathrm{HH}}{ }^{\mathrm{s}}-\mathrm{S}_{\mathrm{Vv}}{ }^{\mathrm{s}}\right)\right\rangle \\
& 4\left\langle\left|\left(\mathrm{~S}_{\mathrm{HV}}{ }^{\mathrm{M}}\right) \cdot\left(\mathrm{S}_{\mathrm{HV}}{ }^{\mathrm{S}}\right)\right|\right\rangle
\end{aligned}
$$

Here, \langle\rangle is ensemble average for SAR image pair, * is complex conjugate.

$$
\mathrm{T}=\left[\begin{array}{lll}
\mathrm{T}_{11} & \mathrm{~T}_{12} & \mathrm{~T}_{13} \\
\mathrm{~T}_{21} & \mathrm{~T}_{22} & \mathrm{~T}_{23} \\
\mathrm{~T}_{31} & \mathrm{~T}_{32} & \mathrm{~T}_{33}
\end{array}\right]
$$

After multiplying the master and slave images, coherency matrix was obtained. To avoid the ambiguity of Hermitian property of coherency matrix modules of diagonal elements are taken.

\section{PolSAR based decomposition of coherency matrix}

Decomposition modelling is used for retrieving the scattering elements from coherency matrix. Huyen (1970) first used the target decomposition technique. Cloude and Pottier (1996) reviewed the potential of different decomposition modelling approaches for scattering information retrieval from PolSAR data. There are two types of decomposition modelling, coherent decomposition and incoherent decomposition. Three types of scattering mechanisms; surface scattering, double bounce and volume scattering were deliberated by the Freeman-Durden decomposition model (Freeman and Durden, 1998). The Yamaguchi decomposition model (Yamaguchi et al., 2011) considers four scattering mechanism surface, double-bounce, volume and helix scattering. The Multiple Component Scattering Model (Zhang et al., 2008) considers five scattering mechanism surface, double-bounce, volume, helix and wire scattering. Yamaguchi decomposition model:

$$
\mathrm{T}=\mathrm{P}_{\mathrm{s}} \mathrm{T}_{\mathrm{s}}+\mathrm{P}_{\mathrm{d}} \mathrm{T}_{\mathrm{d}}+\mathrm{P}_{\mathrm{v}} \mathrm{T}_{\mathrm{v}}+\mathrm{P}_{\mathrm{h}} \mathrm{T}_{\mathrm{h}}
$$

where, $P_{s}, P_{d}, P_{v}, P_{h}$ are power for surface, double-bounce, volume, helix scattering and $\mathrm{T}_{\mathrm{s}}, \mathrm{T}_{\mathrm{d}}, \mathrm{T}_{\mathrm{v}}, \mathrm{T}_{\mathrm{h}}$ are the expansion matrix for surface, double-bounce, volume, helix scattering (Yamaguchi et al., 2011).

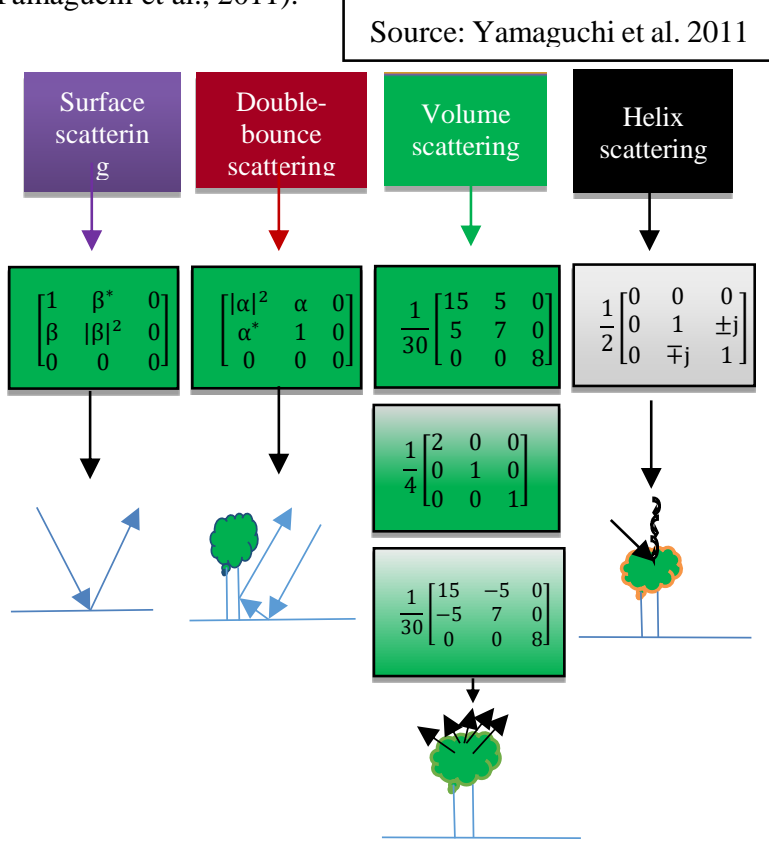

Figure 2: Yamaguchi decomposition model

\section{Field Survey (Barkot Forest)}

The field survey for data collection was carried out for Barkot forest during November 10th to December 5th, 2014. Forty-nine sample plots were taken into observation for the research. Fortyfive sample plots data were already available and four more sample plots were chosen for the study. Stratified random sampling was used to collect field data for the measurement of circumference at breast height $(\mathrm{CBH})$ ranged from $15 \mathrm{~cm}$ to 230 $\mathrm{cm}$. These were later converted to diameter at breast height (DBH) for AGB calculation. Square plotting of 0.1 ha $(31.62 \mathrm{~m}$ $\times 31.62 \mathrm{~m}$ ) with square shaped sample plots were used. By the utilizing of $\mathrm{DBH}$ and tree height estimated the AGB. For the calculating AGB (as shown in equation 9) need to volumetric equation and specific gravity. So forest survey of India defines the volumetric equation (Forest Survey of India, 1996) and Indian woods (Limaye and Sen, 1956) define the specific woods. FSI equation (stem volume equation and species gravity volume) is known for all the species. Four plots were analysed with FSI equation and result in the biomass of $237.22\left(\mathrm{t} \mathrm{ha}^{-1}\right), 264.59$ ( $\mathrm{t}$ ha $\left.{ }^{1}\right), 221.42\left(\mathrm{t} \mathrm{ha}^{-1}\right)$ and $282.92\left(\mathrm{t} \mathrm{ha}^{-1}\right)\left(1\right.$ hectare $\left.=10000 \mathrm{~m}^{2}\right)$. Positional errors of $6 \mathrm{~m}$ to $9 \mathrm{~m}$ were observed in GPS readings during the field data collection. Table 3 defines parameters that have been measured and methods that have been applied for the tree height and $\mathrm{CBH}$. Final AGB calculated ranged between $112.58\left(\mathrm{t} \mathrm{ha}^{-1}\right)-356.08\left(\mathrm{tha}^{-1}\right)$. The details of various forest types wise sample plot in Table 2 and field parameters recorded are described in Table 3.

AGB equation is given as follow

$\mathrm{AGB}=$ stem volume $\times$ specific gravity 


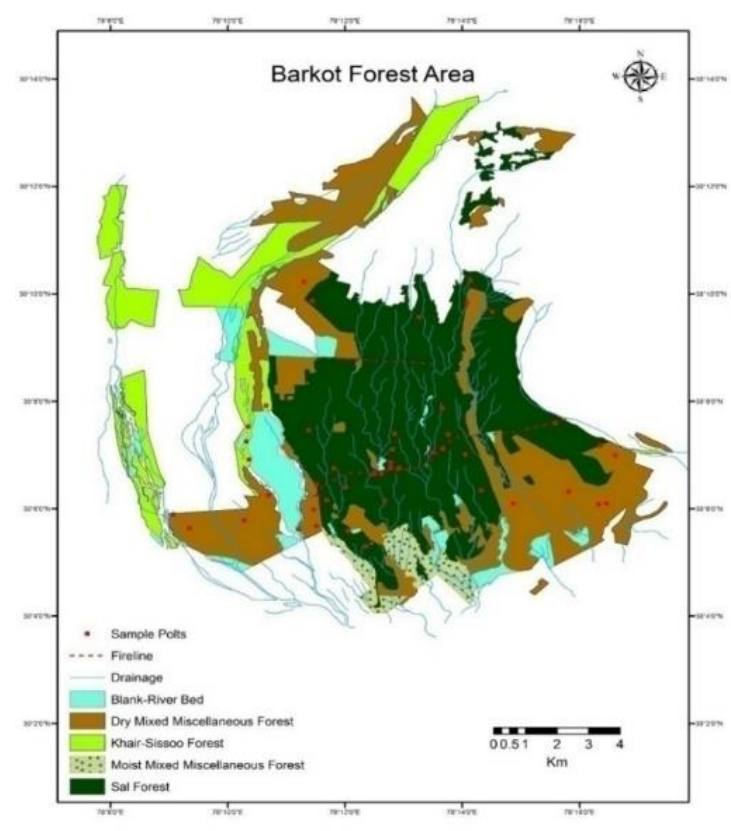

Figure 3: The field area consisting Sal forest, dry mixed miscellaneous forest, Khair-Sissoo forest and moist mixed miscellaneous forest. Most of the points lie in the Sal area since $57 \%$ area is covered by Sal forest

Source: Chandola 2013

Table 2: Various forest types where Forty-nine sample plots are collected

\begin{tabular}{|l|l|}
\hline Forest type & Plots \\
\hline Sal Forest and Mix Sal Forest & 23 \\
\hline Teak Plantation & 9 \\
\hline Mix Teak Plantation & 4 \\
\hline Acacia & 2 \\
\hline Holoptelea Plantation & 5 \\
\hline Mixed Forest & 6 \\
\hline
\end{tabular}

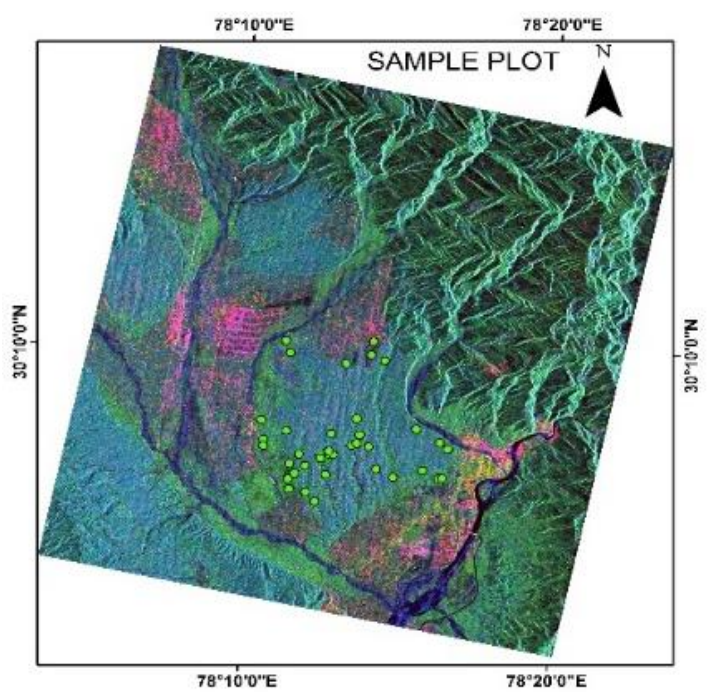

Figure 4: Sample Plot location in Barkot Forest Area
Table 3: Description of field data

\begin{tabular}{|l|l|}
\hline Parameters Measured & Method \\
\hline Number of Samples Plots & 49 \\
\hline Size of Sample Plots & $31.62 \mathrm{~m} \times 31.62 \mathrm{~m}$ \\
\hline Shape of Sample Plots & Square \\
\hline $\mathrm{CBH}$ & $\begin{array}{l}\text { Measurement } \\
\text { circumference at breast } \\
\text { height }\end{array}$ \\
\hline Tree height & $\begin{array}{l}\text { Measured using laser } \\
\text { dendrometer }\end{array}$ \\
\hline
\end{tabular}

\section{STUDY AREA AND DATASETS}

\subsection{Study area}

The study area is Barkot forest, located between $28^{\circ} 43^{\prime} \mathrm{N}$ to $31^{\circ} 27^{\prime} \mathrm{N}$ (latitude) and $77^{\circ} 34^{\prime} \mathrm{E}$ to $81^{\circ} 02^{\prime} \mathrm{E}$ (longitude) in Uttarakhand state in the northern part of India. The study area situated in Shivalik range of Himalayas. The central part of the study area is Rajaji National Park, which is moderately mountainous with elevation ranging from 100 to $450 \mathrm{~m}$. Study area contain tropical and subtropical moist broadleaf forest. Barkot forest is covered with grasses, shrubs, Shorea robusta (Sal) and Khair-sissoo forest, Tectona grandis (Teak) and Mallotus philippensis (Rohini). This forest is gregarious in nature with mature Sal trees growing.

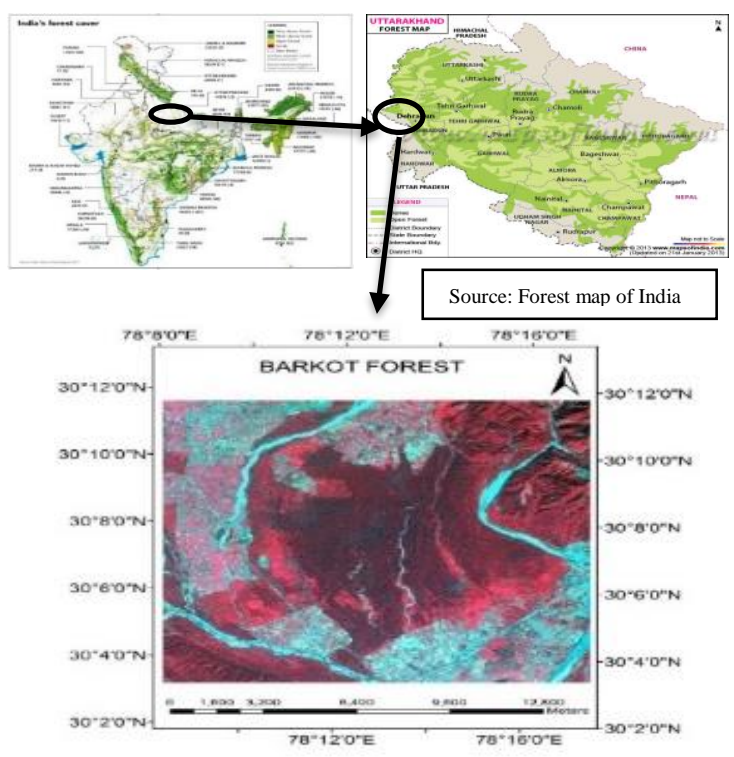

Figure 5: Study Area of Barkot Forest Dehradun, India

In Dehradun district three types of Sal forest are found as dry shiwalik Sal forest, moist Bhabar Doon, moist Shiwalik forest. The area under study is $1800 \mathrm{~km}^{2}$. Flora and fauna is the famous part of the Rajaji national part, which is situated of border of Barkot forest. This area suitable in this project because it provides all types of scattering as surface scattering, doublebounce scattering and volume scattering which are needed in this project. Study area is surrounded by agricultural area which provides ample volume scatterers through the growing period. The same area, without any vegetation growth provide surface scattering near the Barkot forest. This provides us with another opportunity to study the interaction of different scatterers of microwave. The terrain is relatively plain and hence the layover 
and shadow effect are not visible in the study area. Barkot forest is located in the vicinity of the organization so it is convenient for field data collection.

\subsection{Datasets}

Single look complex (SLC) Radrasat-2 data is used in this study. Data acquired in fully polarized in $\mathrm{C}$ band data with wavelength $5.55 \mathrm{~cm}$. This data was fully polarized based data and both the images were accessed with the gap of 23 days

Table 4: Information Regarding Radarsat-2 dataset

\begin{tabular}{|c|c|c|c|}
\hline Date of acquisition & Beam & \begin{tabular}{l}
\multicolumn{2}{l}{ Incidence } \\
angle (Far \\
range)
\end{tabular} & $\begin{array}{l}\text { Incidence } \\
\text { angle (near } \\
\text { range) }\end{array}$ \\
\hline $\begin{array}{l}\text { 28th January } 2014 \\
\text { (Master image) }\end{array}$ & Q14 & $35.0^{\circ}$ & $33.4^{\circ}$ \\
\hline $\begin{array}{l}\text { 20th February } \\
2014 \text { (Slave } \\
\text { image) }\end{array}$ & Q14 & $35.0^{\circ}$ & $33.4^{\circ}$ \\
\hline
\end{tabular}

Source: Product files (Radarsat -2 data)

\section{RESULT}

This research paper concerns with the results achieved using the adopted methodology. The present research work was attempted to estimate aboveground biomass using semi-empirical modelling approach (EWCM). PolInSAR based coherency matrix was used in this study. PolInSAR image was generated through the co-registration of the master and slave images. Polarimetric decomposition modelling was used to obtain the scattering elements i.e. volume scattering, double-bounce scattering and surface scattering. This information was used to derive parameters required for semi-empirical modelling i.e. EWCM for the AGB estimation. Field data was also collected for the validation. The model derived biomass was compared with the field biomass. Accuracy assessment was accomplished using two statistical parameters i.e. $\mathrm{R}^{2}$ and RMSE to judge the potential of modelling approach.

\section{Biomass estimation from EWCM}

The semi-empirical model i.e. EWCM is defined in above section. Modelled AGB equation 20 was used to estimate biomass. The results are shown in following sections.

\section{Field AGB and Modelled AGB}

Figure 6 shows the linear regression between field AGB and modelled biomass. The $\mathrm{R}^{2}$ value is 0.47 , the modelled AGB show RMSE equal to $55.18\left(\mathrm{t} \mathrm{ha}^{-1}\right)$ and accuracy for model output is $72.13 \%$. RMSE is calculated utilizing the formula as given in equation 18.

$$
R M S E=\sqrt{\sum_{i=1}^{N} \frac{(\text { mesured biomass-estmated biomass })^{2}}{N}}
$$

Where, measured biomass is modelled biomass, estimated biomass is field biomass and $N$ is the number of sample plots utilized in modelled biomass. Percent accuracy is calculated utilizing the formula in equation 19.

Accuracy $(\%)=\left[1-\frac{1}{N} \sum_{i=1}^{N} \frac{\text { measured biomass -estimated biomass }}{\text { estimated biomass }}\right] * 100$
The precision of the modelled estimated biomass explains the relevance of the modelling procedure as it demonstrates how close the model estimated biomass to the field estimated biomass. 72.13 percent accuracy was achieved for the measured biomass.

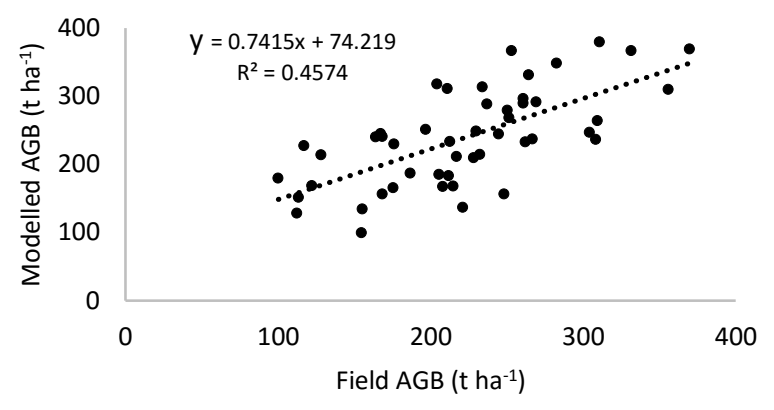

Figure 6: - Co-relation between field AGB (x axis) and modelled AGB (y axis) for 49 plots.

\section{Retrieval of $\beta$ value for estimation of modelled biomass}

Some plots (15 plots) of the field data were used for estimation of semi-empirically defined coefficient $\beta$ and remaining 34 plots were used for accuracy assessment. Equation 20 was utilized to find $\beta$ value for the estimation of modelled biomass. This equation shows the empirically defined coefficient $(\beta)$ and AGB (B)

$$
\begin{aligned}
& \beta=-\frac{1}{B} \ln \left(\frac{\sigma_{f o r}^{0}-\sigma_{v e g}^{0}}{\sigma_{g r}^{0}-\sigma_{v e g}^{0}+\sigma_{g s}^{0}}\right) \\
& B=-\frac{1}{\beta} \ln \left(\frac{\sigma_{f o r}^{0}-\sigma_{v e g}^{0}}{\sigma_{g r}^{0}-\sigma_{v e g}^{0}+\sigma_{g s}^{0}}\right)
\end{aligned}
$$

$\beta$ is calculated by utilizing the field data information. $\mathrm{R}^{2}$ comes out to be 0.5299 for $\beta$ (as shown in fig 6)

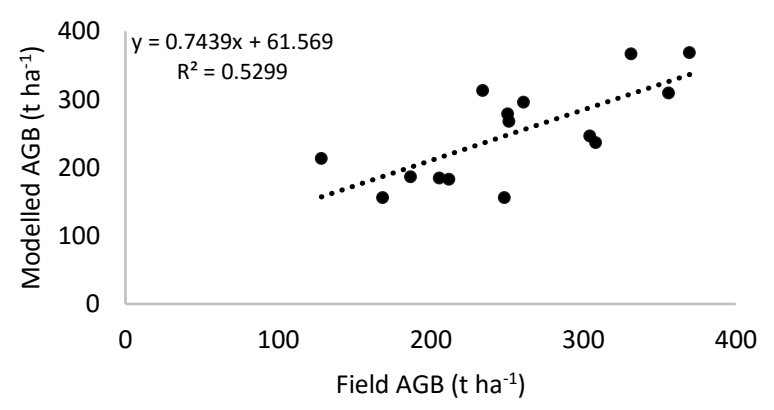

Figure 7: - Linear regression between modelled biomass (y axis) and field biomass (x axis) for the 15 plots.

Figure 7 shows the linear regression between field biomass and modelled biomass for the 15 plots were used for calculation of empirically defined coefficient value. From the 15 plots, correlation coefficient value was observed to be 0.0024 . The $\mathrm{R}^{2}$ between modelled biomass and the field biomass was 0.5299 for the fifteen plots. The field biomass was utilized for the validation of modelled biomass. The table 5 indicates RMSE value equal to $50.17\left(\mathrm{t} \mathrm{ha}^{-1}\right)$ and percent accuracy of 78.6 for 15 plots. These 15 plots show higher accuracy as compared to the remaining 34 plots. 
Modelled biomass for the remaining 34 plots

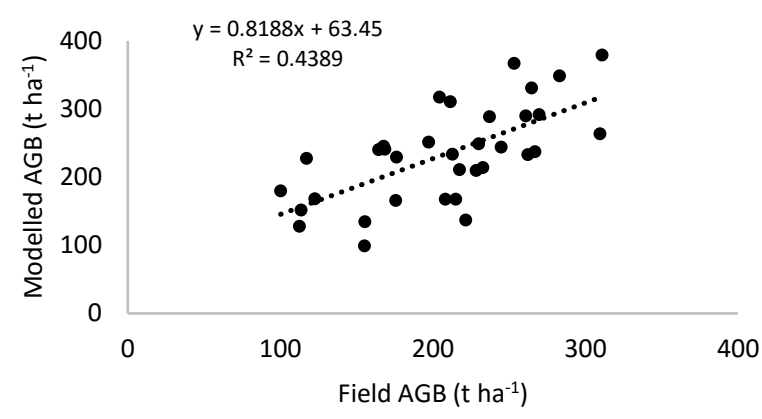

Figure 8: - Linear regression between modelled biomass (y axis) and field biomass (x axis) for the 34 plots.

Figure 8 shows the linear regression between field biomass and modelled biomass for the 34 plots to estimate the AGB. The $\mathrm{R}^{2}$ between the modelled biomass against the field biomass came out to be 0.438 . This graph also shows that most of the value of modelled biomass varies from $150\left(\mathrm{t} \mathrm{ha}^{-1}\right)$ to $300\left(\mathrm{t} \mathrm{ha}^{-1}\right)$. The remaining 34 plots gives RMSE of $58.8\left(\mathrm{t} \mathrm{ha}^{-1}\right)$ and percent accuracy of $69.09 \%$.

Table 5: -RMSE and Accuracy (\%) obtained for modelled AGB

\begin{tabular}{|c|c|c|c|c|c|c|c|c|}
\hline \multicolumn{9}{|c|}{ Modelled AGB } \\
\hline \multicolumn{2}{|c|}{ Total forty-nine plots } & \multicolumn{3}{c|}{ Fifteen plots } & \multicolumn{3}{c|}{ Thirty-four plots } \\
\hline$R^{2}$ & RMSE & $\%$ & $R^{2}$ & RMSE & $\%$ & $R^{2}$ & RMSE & $\%$ \\
\hline 0.47 & 55.18 & 72.13 & 0.52 & 50.17 & 78.6 & 0.43 & 58.8 & 69.09 \\
\hline
\end{tabular}

Table 5 shows the $\mathrm{R}^{2}$, RMSE and percent accuracy for the modelled AGB. The estimated AGB using EWCM is showing reasonable accuracy when the de-oriented PolInSAR image are used. The EWCM Modelled AGB has an RMSE of 55.18 ( $\mathrm{t}$ ha 1) and a percent accuracy of 72.13. $\beta$ is used for the fifteen plots and shows RMSE of $50.17\left(\mathrm{t} \mathrm{ha}^{-1}\right)$ and a percent accuracy of 78.6. Remaining 34 plots are utilized for estimated AGB and shows RMSE of $58.8\left(\mathrm{t} \mathrm{ha}^{-1}\right)$ and percent accuracy of 69.09.

\section{DISCUSSION}

The estimation of AGB using a semi-empirical modelling approach i.e. EWCM. Three parameters i.e. surface scattering, double bounce and volume scattering were retrieved from the scattering information. The field biomass for 15 plots along with the EWCM approach was used to obtain fourth parameter $(\beta)$. AGB was estimated with help of model inversion of EWCM.

The regression analysis was done for the modelled biomass against the field biomass. For the accuracy assessment statistical parameter such as RMSE as well as percentage accuracy was used. The scatter plot was generated for 49 plots between the biomass estimated from EWCM and the field biomass. The same procedure was followed for the 15 plots and 34 plots as well. All the three scatter plots show a positive correlation between the biomass estimated from EWCM and the field biomass. The highest $\mathrm{R}^{2}$ was found to be 0.5299 for the 15 plots.

In this research work fully polarimetric data was utilized. Fully Polarimetric data contains all type of scattering information that is needed in the EWCM model. The main purpose of using fully Polarimetric SAR data is lesser ambiguity for scatterer information and site dependence, which is better than in situ measurement for every scatterer which is time consuming. However, the uncertainties in the stem-volume volumetric equation (FSI, 1996) and specific gravity data are the factors which can be further improved upon. As destructive sampling is prohibited in India and there is also limited amount of time for research, the data provided by FSI is the only feasible option available. The accuracy from GPS readings is very low which is compensated by taking the reading over homogeneous plots.

The estimated AGB using EWCM shows reasonable accuracy when the de-oriented PolInSAR image was used. The EWCM Modelled AGB had an RMSE of 55.18 ( $t$ ha-1) and a percent accuracy of 72.13. $\beta$ was used for the fifteen plots and displays RMSE of $50.17\left(\mathrm{t} \mathrm{ha}^{-1}\right)$ and a percent accuracy of $78.6 \%$. Remaining 34 plots were utilized for estimated AGB and showed RMSE of $58.8\left(\mathrm{t} \mathrm{ha}^{-1}\right)$ and percent accuracy of $69.09 \%$. In the regression analysis conducted by Chandola (Chandola, 2014) between modelled biomass and field biomass, the $\mathrm{R}^{2}$ came out to be 0.496 . In the present study, the $\mathrm{R}^{2}$ between modelled biomass and field biomass was 0.47 . The variations in the results may be due to the difference in the season of the dataset used. In a work by Poolla (Poolla, 2013) the value of $\mathrm{R}^{2}$ was 0.431 whereas, in the current study $\mathrm{R}^{2}$ was 0.47 between modelled biomass and field biomass. The difference in the values could be because of different wavelength data used i.e. L-band data used by Poolla (Poolla, 2013) and C-band in current work although the modelling approach used is same i.e. EWCM. The other reason is that present study uses the two co-registered images i.e. PolInSAR image.

\section{CONCLUSION}

The present study focuses on the retrieval of aboveground forest biomass using polarimetric scattering information and a semiempirical EWCM. The estimated AGB using PolInSAR and EWCM shows reasonable accuracy. Based on the fifteen plots, correlation between field biomass (X axis) and modelled biomass ( $\mathrm{Y}$ axis) was shown to be $\left(\mathrm{R}^{2}=0.5299\right)$, remaining thirty-four plots show the correlation between field biomass ( $\mathrm{X}$ axis) and modelled biomass ( $\mathrm{Y}$ axis) as $\left(\mathrm{R}^{2}=0.43\right)$ and total 49 plots show correlation between field biomass (X axis) and modelled biomass ( $\mathrm{Y}$ axis) as $\left(\mathrm{R}^{2}=0.47\right)$. For Barkot forest zone, modelled biomass shows RMSE as 55.18 (tons/ha) and the accuracy was $72 \%$, which relate positively with the field data. Further study is recommended using different data sets in L-band and P-band for the assessment of AGB.

\section{REFERENCES}

Amrutkar, R.P., Kumar, S., Kushuwaha, S.P.S., Bhatt, G.D., 2012. Forest biophysical parameter retrieval using PolSAR technique, in: 8th International Conference on Microwaves, Antenna, Propagation \& Remote Sensing-ICMARS, Jodhpur, India.

Attema, E.P.W., Ulaby, F.T., 1978. Vegetation modeled as a water cloud. Radio Science 13,357-364. doi:10.1029/RS013i002p00357.

Ballester-Berman, J.D., Lopez-Sanchez, J.M., 2010. Applying the Freeman\&\#x2013; Durden Decomposition Concept to Polarimetric SAR Interferometry. IEEE Transactons on Geoscience Remote Sensing 48, 466-479. doi:10.1109/TGRS.2009.2024304.

Chandola, S., 2014. Polarimetric SAR Interferometry for Forest AGB Estimation. M.Sc. Thesis Faculty of Geo-information 
Science and Earth Observation (ITC) of the University of Twente, Enschede, The Netherlands.

Chen, S.-W., Wang, X.-S., Sato, M., 2012. PolInSAR Complex Coherence Estimation Based on Covariance Matrix Similarity Test. IEEE Transactions on Geoscience and Remote Sensing 50, 4699-4710. doi:10.1109/TGRS.2012.2192937.

Chowdhury, T., Thiel, C., Schmullius, C., Stelmaszczuk-Górska, M., 2013. Polarimetric Parameters for Growing Stock Volume Estimation Using ALOS PALSAR L-Band Data over Siberian Forests. Remote Sens. 5, 5725-5756. doi:10.3390/rs5115725

Cloude, S.R., 2008. PolInSAR training course. Tutorial ESA Polarimetry. SAR Process. PolSARPro Toolbox.

Cloude, S.R., Papathanassiou, K.P., 1998. Polarimetric SAR interferometry. IEEE Transactions on Geoscience and Remote Sensing 36, 1551-1565.

Cloude, S.R., Pottier, E., 1996. A review of target decomposition theorems in radar polarimetry. IEEE Transactions on Geoscience and Remote Sensing. On 34, 498-518. doi:10.1109/36.485127

Dinh, H.T.M., Rocca, F., Tebaldini, S., d' Alessandro, M.M., Le Toan, T., Villard, L., 2012. Relating tropical forest biomass to Pband SAR tomography, in: Geoscience and Remote Sensing Symposium (IGARSS), 2012 IEEE International. IEEE, pp. 7589-7592.

Food and Agriculture Organization of the United Nations, 2004. Global forest resources assessment update 2005 terms and definitions. Food and Agriculture Organization of the United Nations, Rome, Italy.

Forest Survey of India, 1996. Volume Equation for Forests of India, Nepal and Bhutan. Ministry of Environment and Forests, Dehradun, India.

Freeman, A., Durden, S.L., 1998. A three-component scattering model for polarimetric SAR data. IEEE Transactions on Geoscience and Remote Sensing 36, 963-973.

Hellmann, M., Cloude, S.R., 2005. Polarimetric interferometry and differential interferometry. Adelaide University School of Electrical and Electronic Engineering., Australia.

Hermitian matrix [WWW Document], 2015. Wikipedia. URL http://en.wikipedia.org/wiki/Hermitian_matrix_ (accessed 4.21.15).

Huynen, J.R., 1970. Phenomenological theory of radar targets, $\mathrm{PhD}$ thesis. Technical University, Delft, Netherlands.

Kirilenko, A.P., Sedjo, R.A., 2007. Climate change impacts on forestry. Proceedings National Academy Science 104, 1969719702. doi:10.1073/pnas.0701424104.

Kumar, S., Pandey, U., Kushwaha, S.P., Chatterjee, R.S., Bijker, W., 2012. AGB estimation of tropical forest from Envisat advanced synthetic aperture radar data using modeling approach. Journal Applied Remote Sensing 6, 063588-063588

Lee, J.-S., Ainsworth, T.L., 2011a. The Effect of Orientation Angle Compensation on Coherency Matrix and Polarimetric Target Decompositions. IEEE Transactions on Geoscience and Remote Sensing 49, 53-64. doi:10.1109/TGRS.2010.2048333
Lee, J.-S., Pottier, E., 2009. Polarimetric Radar Imaging: From Basics to Applications. CRC Press, Florida.

Limaye, V.D., Sen, B.R., 1956. Weight and Specific Gravity of Indian Woods. Forest Research Institute, Indian Forest Records, Dehradun, India.

Li, Z., Bethel, J., 2008. Image co-registration in SAR interferometry. Proc International Archives Photogrammetry Remote Sensing Spatial Information Sciences 433-438.

Main-Knorn, M., Moisen, G.G., Healey, S.P., Keeton, W.S., Freeman, E.A., Hostert, P., 2011. Evaluating the Remote Sensing and Inventory-Based Estimation of Biomass in the Western Carpathians. Remote Sens. 3, 1427-1446. doi:10.3390/rs3071427.

Mette, T., Papathanassiou, K., Hajnsek, I., 2004. Biomass estimation from polarimetric SAR interferometry over heterogeneous forest terrain, in: Geoscience and Remote Sensing Symposium, 2004. IGARSS'04. Proceedings. 2004 IEEE International. IEEE, pp. 511-514.

Minh, N.P., Zou, B., Lu, D., 2012. Accuracy improvement method of forest height estimation for PolInSAR Image, in: Audio, Language and Image Processing (ICALIP), 2012 International Conference on. IEEE, pp. 594-598.

Papathanassiou, K.P., Cloude, S.R., 2001. Single-baseline polarimetric SAR interferometry. IEEE Transactions on Geoscience and Remote Sensing 39, 2352-2363.

Poolla, S. bharadwaj, 2013. Polarimetric scattering model for biophysical characterization of multilayer vegetation using space borne PolSAR data. M.Sc. Thesis Faculty of Geo-information Science and Earth Observation (ITC) of the University of Twente, Enschede, The Netherlands.

Santoro, M., 2003. Estimation of biophysical parameters in boreal forests from ERS and JERS SAR interferometry. Ph. D Thesis Department of Radio and Space Science, Chalmers University of Technology.

Touzi, R., 2007. Target Scattering Decomposition in Terms of Roll-Invariant Target Parameters. IEEE Transactions on Geoscience. Remote Sensing 45, 73-84. doi:10.1109/TGRS.2006.886176

Touzi, R., Boerner, W.M., Lee, J.S., Lueneburg, E., 2004. A review of polarimetry in the context of synthetic aperture radar: concepts and information extraction. Canadian Journal Remote Sensing 30, 380-407.

Wollersheim, M., Collins, M.J., 2008. Extraction of Forest Biophysical Parameters Using Polarimetric SAR, in: Geoscience and Remote Sensing Symposium, 2008. IGARSS 2008. IEEE International. IEEE, pp. II-625.

Woodhouse, I.H., 2006. Introduction to microwave remote sensing. Taylor \& Francis, Boca Raton.

Yamaguchi, Y., Sato, A., Boerner, W.-M., Sato, R., Yamada, H., 2011. Four-Component Scattering Power Decomposition with Rotation of Coherency Matrix. IEEE Transactions on Geoscience. Remote Sensing 49, 2251-2258. doi:10.1109/TGRS.2010.2099124 